\title{
Adding chemotherapy to TKI: can we improve first-line treatment for EGFR-mutated NSCLC patients?
}

\author{
Francesco Passiglia, Antonio Russo \\ Department of Surgical, Oncological and Oral Sciences, Section of Medical Oncology, University of Palermo, Palermo, Italy \\ Correspondence to: Antonio Russo, MD, PhD. Department of Surgical, Oncological and Oral Sciences, Section of Medical Oncology, University of \\ Palermo, Via del Vespro 129 - 90127, Palermo, Italy. Email: antonio.russo@usa.net. \\ Comment on: Cheng Y, Murakami H, Yang PC, et al. Randomized Phase II Trial of Gefitinib With and Without Pemetrexed as First-Line Therapy in \\ Patients With Advanced Nonsquamous Non-Small-Cell Lung Cancer With Activating Epidermal Growth Factor Receptor Mutations. J Clin Oncol \\ 2016;34:3258-66.
}

Submitted Dec 01, 2016. Accepted for publication Dec 15, 2016.

doi: $10.21037 /$ tcr.2016.12.32

View this article at: http://dx.doi.org/10.21037/tcr.2016.12.32

In The Fournal of Clinical Oncology, Ying Cheng and colleagues (1) have recently reported the results of a phase II randomized trial comparing pemetrexed plus gefitinib $v s$. gefitinib in treatment-naive, East Asian patients, with advanced non-squamous non-small cell lung cancer (NSCLC) and activating epidermal growth factor receptor (EGFR) mutations. The study met its primary end-point in the intent-to-treat population, showing a significantly longer median progression free survival (PFS) in favors of the combination arm (15.8 months) compared to single agent arm (10.9 months) [hazard ratio (HR): 0.68; $95 \%$ CI, 0.48 to 0.96 ; one-sided $\mathrm{P}=0.014$; two-sided $\mathrm{P}=0.029$ ]. The significant improvement in PFS was independent from the specific type of mutation (EGFR exon 19 deletion $v s$. EGFR exon 21 L858R point mutation). The addition of pemetrexed to gefitinib resulted also in a significantly longer time to progressive disease (16.2 vs. 10.9 months; HR: 0.66 ; $95 \% \mathrm{CI}, 0.47$ to 0.93$)$ and duration of response (15.4 vs. 11.3 months; HR: 0.74 ; $95 \%$ CI, 0.50 to 1.08 ), while no differences in response rate (RR: $80 \%$ vs. $74 \%$ ) were observed between the two treatment arms. As attended, the percentage of patients who reported grade 3-4 drug-related adverse-events (AEs) was significantly higher ( $42 \%$ vs. $19 \%$ ) in the combination arm, as well as the proportion of patients who discontinued treatment because of AEs nearly doubled with pemetrexed plus gefitinib compared to single agent arm.

Several randomized phase III studies (2-10) previously showed that EGFR-tyrosine kinase inhibitors (TKIs) significantly improve both RR, PFS and quality of life (QoL) compared to platinum-based doublets chemotherapy as first-line treatment of EGFR-mutated NSCLC patients. Subsequently a pooled analysis of both LuxLung3 and LuxLung6 trials has also shown an overall survival (OS) benefit in favor of the EGFR-TKI Afatinib, even if it was limited to the subgroup of patients with EGFR exon 19 deletion (9). Overall, the results of all such studies convincingly and consistently demonstrated that for the subgroup of patients whose tumors harbor an EGFR activating mutation, the optimal strategy is starting with an EGFR-TKI, including gefitinib, erlotinib, or afatinib $(11,12)$.

The trial conducted by Ying Cheng and colleagues (1) suggests that the addition of chemotherapy to the EGFRTKI may further improve the outcomes of EGFR-mutated, non-squamous NSCLC patients.

Pre-clinical studies have shown a potential synergism between the EGFR-TKI, erlotinib, and the multi-targeted antifolate pemetrexed in NSCLC cell-lines $(13,14)$. The modulation of both EGFR and Akt phosphorylation, together with a significant decrease of thymidylate synthase (TS) expression and activity in all NSCLC cells, represent the molecular mechanisms underlying such synergistic interaction. Later, early phase I-II studies demonstrated both a promising activity and a tolerable safety profile of EGFRTKI plus pemetrexed combination in pre-treated NSCLC patients (15), with a significantly longer PFS compared to either drug alone in a clinically selected population of neversmokers with non-squamous histology (16).

Several phase III studies investigated the efficacy of EGFR-TKI in combination with chemotherapy in first- 
line treatment (17-20), showing no survival benefit with combinations, likely because wild-type patients were also enrolled. Among these, CALGB30406 study (21) evaluated erlotinib with and without platinum-chemotherapy in clinically selected patients with advanced lung adenocarcinoma who were never or light former smokers, showing similar efficacy between the two treatment arms in the overall study population. A subsequent EGFRmutation analysis revealed that patients with EGFRpositive tumors were most likely to benefit, reaching a median PFS of 14.1 months, and OS of 31.3 months with erlotinib, even higher (PFS: 17.2 months, OS: 38.1 months) in the combination arm. Such data suggested that EGFR-TKIs synchronously combined with chemotherapy could improve survival in molecular selected subsets of patients. Similarly the FASTACT2 randomized phase III study (22) also showed a survival benefit of a first-line intercalated regimen of chemotherapy and erlotinib in EGFR-mutated NSCLC patients.

Recently the NEJ005 randomized phase II study (23) prospectively compared concurrent gefitinib plus carboplatin/pemetrexed regimen $v s$. sequential alternating regimen in East-Asian, EGFR-mutated NSCLC patients. The results of such study showed a favorable trend in PFS (18.3 vs. 15.3 months; HR: 0.71; 95\% CI, 0.42-1.20; $\mathrm{P}=0.20)$ and a significant improvement in OS (41.9 vs. 30.7 months; HR: 0.51; 95\% CI, 0.26-0.99; $\mathrm{P}=0.042)$, in favor of the concurrent regimen arm, first demonstrating the superiority of the upfront combination of gefitinib and carboplatin/pemetrexed, which is currently investigated in the ongoing phase III NEJ009 study. The trial conducted by Ying Cheng and colleagues (1) suggested that adding single-agent chemotherapy to EGFR-TKI in firstline may be sufficient to improve outcomes of EGFRmutated patients. The results are intriguing, but need to be interpreted in light of the recent NEJ005 study. The PFS improvement is consistent across both studies, and is more favorable in comparison to the 9-10 months PFS observed in previous studies of first-line gefitinib monotherapy in EGFR-mutated NSCLC patients (2). It could be likely related to the activity of early concurrent use of cytotoxic agents against de-novo resistance alterations, but the lack of tissue samples collection for biomarker analysis, limited the possibility to evaluate molecular data. However, it will be important to see whether the addition of pemetrexed to gefitinib will also lead to an OS benefit. Indeed, OS improvement is crucial in order to evaluate the optimal treatment sequence in this setting of patients, and ultimately accept the increased adverse events and cost of a potential upfront combination. Even if authors declare that "platinum-based therapies may still be used after progression", the patients included in the experimental arm will never receive the standard treatment option, which is platinum-pemetrexed combination followed by pemetrexed maintenance therapy (24), and this could negatively affect their final OS.

Furthermore we need to discuss the clinical benefit obtained with chemotherapy plus gefitinib combination considering the other promising treatment option emerging in this setting.

The addition of bevacizumab to the EGFR-TKI, Erlotinib, reached a median PFS: 16 vs. 9.7 months of erlotinib monotherapy, with about $50 \%$ significant reduction of the risk of progression [HR: $0.54(0.36-0.79)$ ], in East-Asian, EGFR-mutated patients (25). Waiting for the randomized phase III studies currently ongoing both in Asian and Caucasian populations, such combination has recently received the approval by both Food and Drug Administration (FDA) and European Medical Agency (EMA) as first-line treatment. Even more exciting are the data emerging from the first-line cohort of AURA phase I trial (26), which showed an impressive activity of the third generation EGFR-TKI osimertinib, with a median PFS: 19 months and an ORR: 77\%, leading to the ongoing phase III randomized FLAURA trial comparing osimertinib $v$ s. gefitinib/erlotinib in first-line. Despite immunotherapy with anti-PD1/PDL1 single agent seems to be not effective in NSCLC harboring EGFR-mutations (27), several trials are currently investigating potential combinations of checkpoint-inhibitors with EGFR-TKI, in order to further improve the outcomes of these patients.

In conclusion the study of Cheng et al. represent a significant attempt to the improvement of first-line treatments for EGFR-mutated NSCLC patients. The PFS benefit together with a modest increase in toxicity suggest that adding chemotherapy to EGFR-TKI may represent an effective treatment option in this setting. However, as mentioned before, OS benefit is crucial in order to confirm the effectiveness of Pemetrexed plus Gefitinib upfront combination. Finally, considering the advent of new promising drugs/combinations, the main challenge will be how to combine all these agents and ultimately define the optimal treatment sequence for EGFR-mutant NSCLC patients. 


\section{Acknowledgments}

Funding: None.

\section{Footnote}

Provenance and Peer Review: This article was commissioned and reviewed by the Section Editor Shaohua Cui (Department of Pulmonary Medicine, Shanghai Chest Hospital, Shanghai Jiao Tong University, Shanghai, China).

Conflicts of Interest: Both authors have completed the ICMJE uniform disclosure form (available at http://dx.doi. org/10.21037/tcr.2016.12.32). The authors have no conflicts of interest to declare.

Ethical Statement: The authors are accountable for all aspects of the work in ensuring that questions related to the accuracy or integrity of any part of the work are appropriately investigated and resolved.

Open Access Statement: This is an Open Access article distributed in accordance with the Creative Commons Attribution-NonCommercial-NoDerivs 4.0 International License (CC BY-NC-ND 4.0), which permits the noncommercial replication and distribution of the article with the strict proviso that no changes or edits are made and the original work is properly cited (including links to both the formal publication through the relevant DOI and the license). See: https://creativecommons.org/licenses/by-nc-nd/4.0/.

\section{References}

1. Cheng Y, Murakami H, Yang PC, et al. Randomized Phase II Trial of Gefitinib With and Without Pemetrexed as First-Line Therapy in Patients With Advanced Nonsquamous Non-Small-Cell Lung Cancer With Activating Epidermal Growth Factor Receptor Mutations. J Clin Oncol 2016;34:3258-66.

2. Mok TS, Wu YL, Thongprasert S, et al. Gefitinib or Carboplatin-Paclitaxel in Pulmonary Adenocarcinoma. N Engl J Med 2009;361:947-57.

3. Mitsudomi T, Morita S, Yatabe Y, et al. Gefitinib versus cisplatin plus docetaxel in patients with non-small-cell lung cancer harbouring mutations of the epidermal growth factor receptor (WJTOG3405): an open label, randomised phase 3 trial. Lancet Oncol 2010;11:121-8.

4. Maemondo M, Inoue A, Kobayashi K, et al. Gefitinib or chemotherapy for non-small-cell lung cancer with mutated
EGFR. N Engl J Med 2010;362:2380-8.

5. Han JY, Park K, Kim SW, et al. First-SIGNAL: first-line single-agent iressa versus gemcitabine and cisplatin trial in never-smokers with adenocarcinoma of the lung. J Clin Oncol 2012;30:1122-8.

6. Rosell R, Carcereny E, Gervais R, et al. Erlotinib versus standard chemotherapy as first-line treatment for European patients with advanced EGFR mutation-positive non-small-cell lung cancer (EURTAC): a multicentre, open-label, randomised phase 3 trial. Lancet Oncol 2012;13:239-46.

7. Zhou C, Wu YL, Chen G, et al. Erlotinib versus chemotherapy as first-line treatment for patients with advanced EGFR mutation-positive non-small-cell lung cancer (OPTIMAL, CTONG-0802): a multicentre, open-label, randomised, phase 3 study. Lancet Oncol 2011;12:735-42.

8. Sequist LV, Yang JC, Yamamoto N, et al. Phase III study of afatinib or cisplatin plus pemetrexed in patients with metastatic lung adenocarcinoma with EGFR mutations. J Clin Oncol 2013;31:3327-34.

9. Yang JC, $\mathrm{Wu} \mathrm{YL}$, Schuler $\mathrm{M}$, et al. Afatinib versus cisplatin-based chemotherapy for EGFR mutation-positive lung adenocarcinoma (LUX-Lung 3 and LUX-Lung 6): analysis of overall survival data from two randomised, phase 3 trials. Lancet Oncol 2015;16:141-51.

10. Wu $\mathrm{YL}, \mathrm{Zhou} \mathrm{C}, \mathrm{Hu} \mathrm{CP}$, et al. Afatinib versus cisplatin plus gemcitabine for first-line treatment of Asian patients with advanced non-small-cell lung cancer harbouring EGFR mutations (LUX-Lung 6): an open-label, randomised phase 3 trial. Lancet Oncol 2014;15:213-22.

11. Passiglia F, Bronte G, Castiglia M, et al. Prognostic and predictive biomarkers for targeted therapy in NSCLC: for whom the bell tolls? Expert Opin Biol Ther 2015;15:1553-66.

12. Bronte G, Rolfo C, Giovannetti E, et al. Are erlotinib and gefitinib interchangeable, opposite or complementary for non-small cell lung cancer treatment? Biological, pharmacological and clinical aspects. Crit Rev Oncol Hematol 2014;89:300-13.

13. Li T, Ling YH, Goldman ID, et al. Schedule-dependent cytotoxic synergism of pemetrexed and erlotinib in human non-small cell lung cancer cells. Clin Cancer Res 2007;13:3413-22.

14. Giovannetti E, Lemos C, Tekle C, et al. Molecular mechanisms underlying the synergistic interaction of erlotinib, an epidermal growth factor receptor tyrosine kinase inhibitor, with the multitargeted antifolate 
pemetrexed in non-small-cell lung cancer cells. Mol Pharmacol 2008;73:1290-300.

15. Ranson M, Reck M, Anthoney A, et al. Erlotinib in combination with pemetrexed for patients with advanced non-small-cell lung cancer (NSCLC): a phase I dosefinding study. Ann Oncol 2010;21:2233-9.

16. Lee DH, Lee JS, Kim SW, et al. Three-arm randomised controlled phase 2 study comparing pemetrexed and erlotinib to either pemetrexed or erlotinib alone as secondline treatment for never-smokers with non-squamous nonsmall cell lung cancer. Eur J Cancer 2013;49:3111-21.

17. Gatzemeier U, Pluzanska A, Szczesna A, et al. Phase III study of erlotinib in combination with cisplatin and gemcitabine in advanced non-small-cell lung cancer: the Tarceva Lung Cancer Investigation Trial. J Clin Oncol 2007;25:1545-52.

18. Giaccone G, Herbst RS, Manegold C, et al. Gefitinib in combination with gemcitabine and cisplatin in advanced non-small-cell lung cancer: a phase III trial--INTACT 1. J Clin Oncol 2004;22:777-84.

19. Herbst RS, Giaccone G, Schiller JH, et al. Gefitinib in combination with paclitaxel and carboplatin in advanced non-small-cell lung cancer: a phase III trial--INTACT 2. J Clin Oncol 2004;22:785-94.

20. Herbst RS, Prager D, Hermann R, et al. TRIBUTE: a phase III trial of erlotinib hydrochloride (OSI-774) combined with carboplatin and paclitaxel chemotherapy in advanced non-small-cell lung cancer. J Clin Oncol 2005;23:5892-9.

21. Jänne PA, Wang X, Socinski MA, et al. Randomized phase II trial of erlotinib alone or with carboplatin and paclitaxel in patients who were never or light former smokers with

Cite this article as: Passiglia F, Russo A. Adding chemotherapy to TKI: can we improve first-line treatment for EGFR-mutated NSCLC patients? Transl Cancer Res 2016;5(Suppl 7):S1413-S1416. doi: $10.21037 /$ tcr.2016.12.32 advanced lung adenocarcinoma: CALGB 30406 trial. J Clin Oncol 2012;30:2063-9.

22. $\mathrm{Wu}$ YL, Lee JS, Thongprasert S, et al. Intercalated combination of chemotherapy and erlotinib for patients with advanced stage non-small-cell lung cancer (FASTACT-2): a randomised, double-blind trial. Lancet Oncol 2013;14:777-86.

23. Sugawara S, Oizumi S, Minato K, et al. Randomized phase II study of concurrent versus sequential alternating gefitinib and chemotherapy in previously untreated nonsmall cell lung cancer with sensitive EGFR mutations: NEJ005/TCOG0902. Ann Oncol 2015;26:888-94.

24. Paz-Ares LG, de Marinis F, Dediu M, et al. PARAMOUNT: Final overall survival results of the phase III study of maintenance pemetrexed versus placebo immediately after induction treatment with pemetrexed plus cisplatin for advanced nonsquamous non-small-cell lung cancer. J Clin Oncol 2013;31:2895-902.

25. Seto T, Kato T, Nishio M, et al. Erlotinib alone or with bevacizumab as first-line therapy in patients with advanced non-squamous non-small-cell lung cancer harbouring EGFR mutations (JO25567): an open-label, randomised, multicentre, phase 2 study. Lancet Oncol 2014;15:1236-44.

26. Ramalingam S, Yang JC, Lee CK, et al. LBA1_PR: Osimertinib as first-line treatment for EGFR mutationpositive advanced NSCLC: updated efficacy and safety results from two Phase I expansion cohorts. J Thorac Oncol 2016;11:S152.

27. Borghaei H, Paz-Ares L, Horn L, et al. Nivolumab versus Docetaxel in Advanced Nonsquamous Non-Small-Cell Lung Cancer. N Engl J Med 2015;373:1627-39. 